\title{
Nondestructive Evaluation of High Temperature Low-Cycle Fatigue Damage Accumulation in Inconel 718 by Chemical Method
}

\author{
Shin-ichi Komazaki, Yutaka Watanabe, and Tetsuo Shoji \\ Research Institute for Fracture Technology, \\ Faculty of Engineering, \\ Tohoku University, \\ Sendai, Japan
}

\begin{abstract}
In order to develop nondestructive evaluation procedure of fatigue damage in Inconel 718 which is used for components of $\mathrm{H}$-II rocket engine, we investigated correlation between the fatigue life fraction and cracks and slip bands which were observed on the etched cross sectional surface of the fatigued specimens. The main results obtained are as follows. (1) The number of cracks and maximum crack depth become large with increased the fatigue life fraction N/Nf. However, maximum crack depth does not remarkably increase in early stage of the fatigue life, while cracks propagate rather fast in the latter half of the fatigue life. (2) The slip band density can be uniquely correlated with the fatigue life fraction N/Nf. The fatigue damage represented by N/Nf can be evaluated by the chemical etching technique and the damage can be evaluated from the early stage to the last stage of fatigue life.
\end{abstract}

\footnotetext{
Superalloys $718,625,706$ and Various Derivatives Edited by E.A. Loria

The Minerals, Metals \& Materials Society, 1997
} 


\section{INTRODUCTION}

A Ni-base superalloy Inconel 718 is used for high temperature components of $\mathrm{H}$-II rocket engine LE-7. A main injector of the engine is subjected to considerable thermal stresses due to sudden and extreme temperature changes during the engine start-up and stop sequence. The stress amplitude, $\Delta \sigma$, per a combustion test cycle reaches $1570-1760 \mathrm{MPa}$ during the start-up and stop sequence. These repeated stresses can cause low-cycle fatigue of the structures. Failures by lowcycle fatigue(high strain fatigue) have been actually experienced during the combustion tests (1). Therefore, it is strongly required to examine the degree of the fatigue damage in the structure after the combustion tests.

It has been well known that maximum crack size and/or crack density show good correlation with fatigue life fraction, and fatigue damage evaluation methods based on surface crack measurements have been proposed in a few alloys(2),(3). Since crack initiation site is inner surface in most cases and the inner surface is not usually accessible, the nondestructive evaluation based on crack observation is not always applicable to the main injector of the rocket engine. A nondestructive evaluation of the fatigue damage is required to perform from the outer surface of the main injector.

Fatigue damage evaluation based on the change in electromagnetic properties, for example, Barkhausen noise measurement $(4)$ has been reported effective in some alloys, but it is difficult to evaluate directly fatigue damage accumulation with a high accuracy because the changes in electromagnetic properties are not always due to fatigue damage. Therefore, it is required to develop a nondestructive evaluation procedure based on a direct measurement of low-cycle fatigue damage.

In this study, in order to develop a nondestructive method to detect and evaluate the fatigue damage accumulation in Inconel 718 we investigated correlation between the fatigue life fraction and cracks and microstructural changes which were observed on the cross sectional surface of the fatigued specimens.

\section{EXPERIMENTALS}

\section{A. Material}

The chemical composition of Inconel 718 used in this study and its mcchanical propcrtics at room temperature and $600{ }^{\circ} \mathrm{C}$ are given in Table I and Table II, respectively. Round-bar-type fatigue specimens with a gauge length of $17 \mathrm{~mm}$ and a gauge diameter of $4 \mathrm{~mm}$ were machined from a $5.5 \mathrm{~mm}$ thick plate. The specimens were solution-treated at $1045^{\circ} \mathrm{C}$ for 1 hour, followed by the double aging treatment $\left(\left\{760^{\circ} \mathrm{C} / 10 \mathrm{~h}+650^{\circ} \mathrm{C} / 9 \mathrm{~h}\right\} \times 2\right)$.

\section{B. Fatigue Tests}

First of all, load-control fatigue failure test was conducted under fully reversed uniaxial loading at $600^{\circ} \mathrm{C}$ in air over stress range of $1716 \mathrm{MPa}$. Then the interrupted fatigue tests were carried out to prepare samples with different degrees of fatigue damage. The samples with $\mathrm{N} / \mathrm{Nf}$ of $0.18,0.35$, 0.51 and 1.00 were obtained, where the fatigue life "Nf" means the number of cycles giving a failure. To obtain reference data, fatigue failure tests were also carried out at a room temperature over stress range of 1324 and $1716 \mathrm{MPa}$. All tests were conducted at a frequency of $1 \mathrm{cpm}$. The obtained fatigue life data and the usage factor N/Nf of specimens are summarized in Table III.

Table 1 Chemical composition of Incone1718. Table 2 Mechanical properties of Inconel718.

\begin{tabular}{cccccccc}
\hline $\mathrm{Al}$ & $\mathrm{B}$ & $\mathrm{C}$ & $\mathrm{Nb}+\mathrm{Ta}$ & $\mathrm{Co}$ & $\mathrm{Cr}$ & $\mathrm{Cu}$ & $\mathrm{Fe}$ \\
\hline 0.60 & 0.004 & 0.07 & 5.07 & 0.62 & 18.31 & 0.05 & $\mathrm{Bal}$ \\
\hline $\mathrm{Mn}$ & $\mathrm{Mo}$ & $\mathrm{Ni}$ & $\mathrm{P}$ & $\mathrm{S}$ & $\mathrm{Si}$ & $\mathrm{Ti}$ \\
\hline 0.21 & 3.03 & 52.13 & $<0.005$ & $<0.002$ & 0.11 & 1.07 \\
\hline \multicolumn{1}{c}{} & & & & & & & $(\mathrm{wt} \%)$
\end{tabular}

\begin{tabular}{l|cccc}
\hline Temp. & $\begin{array}{l}\text { Yield } \\
\text { strength } \\
(\mathrm{MPa})\end{array}$ & $\begin{array}{c}\text { Tensile Elongation } \\
\text { strength } \\
(\mathrm{MPa})\end{array}$ & $\begin{array}{c}\text { Reduction } \\
\text { of area } \\
(\%)\end{array}$ \\
\hline R.T & 1082 & 1355 & 30.0 & 42.2 \\
$600^{\circ} \mathrm{C}$ & 957 & 1137 & 22.9 & 42.3 \\
\hline
\end{tabular}




\section{Observation of Cracks and Microstructural Changes}

The gauge sections of the fatigued specimens were cut into round bars by cutting off both grips and then the bars were longitudinally cut into two halves. The cross sectional surfaces of the specimens were mechanically polished up to $1 \mu \mathrm{m}$ diamond finish. After polishing, the surfaces of specimens were rinsed with ethanol and dried. Then, in order to observe the initiation and growth behaviors of microcracks and to identify the microstructural changes due to the low-cycle fatigue, they were etched in a solution of $\mathrm{HCl}: 100 \mathrm{ml}, \mathrm{H}_{2} \mathrm{O}: 80 \mathrm{ml}, \mathrm{H}_{2} \mathrm{SO}_{4}: 5 \mathrm{ml}, \mathrm{CuSO}_{4}: 20 \mathrm{~g}$, which is commonly used for metallgraphic examination for nickel alloys (5). After the chemical etching, the etched surfaces were subjected to the optical microscopy and SEM observations.

Table 3 Results of fatigue tests and conditions of interrupted tests.

\begin{tabular}{l|lcccc}
\hline Material & Specimen & $\begin{array}{c}\text { Temperature } \\
{ }^{C} \mathrm{C}\end{array}$ & $\begin{array}{c}\text { Stress range } \\
\Delta \sigma, \mathrm{MPa}\end{array}$ & $\begin{array}{c}\text { Cycles } \\
\mathrm{N}\end{array}$ & $\begin{array}{c}\text { Usage factor } \\
\mathrm{N} / \mathrm{Nf}\end{array}$ \\
\hline \multirow{6}{*}{ Matrix } & FB 1 & & & 42 & 0.18 \\
& FB2 & 600 & 1716 & 84 & 0.35 \\
& FB 3 & & & 120 & 0.51 \\
& FB 4 & & & $237:$ failure & 1.00 \\
& FB R.T175 & R.T & 1716 & $6314:$ failure & - \\
& FB R.T135 & R.T & 1324 & $21860:$ failure & - \\
\hline
\end{tabular}

\section{RESULTS AND DISCUSSION}

\section{A. Crack Observation}

\section{Crack Initiation and Growth Behavior}

The appearance of microcrack initiated at specimens' surfaces at $600^{\circ} \mathrm{C}$ and at room temperature are given in Figure 1 (a) and (b), respectively. As shown in Figure 1(b), a crack tends to initiate and grow along a slip plane at room temperature, and a lot of ditch-like corrosion are observed around the crack. In addition, some cracks preferentially propagated along these ditches. As mentioned in the next paragraphs in detail, these ditch-like corrosion were found to be a trace of slip bands. In contrast to the crack behaviors at room temperature, as shown in Figure $1(\mathrm{a})$, cracks initiated at grain boundary and propagated mainly along grain boundaries at $600^{\circ} \mathrm{C}$, and there is few slip bands observed around such intergranular cracks. However a few cracks were found initiated and grew along the slip plane also in the $600^{\circ} \mathrm{C}$ fatigued specimens.
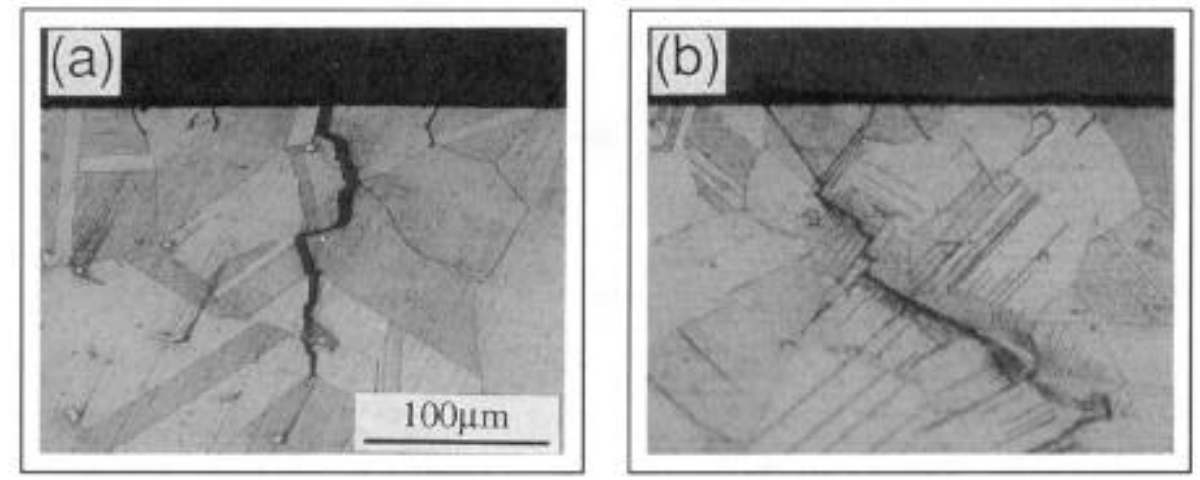

Figure 1 Examples of microcrack growth behavior: (a) Failed specimen at $600^{\circ} \mathrm{C}$ (FB4), (b) Failed specimen at room temperature (FBR.T175). 
In order to investigate quantitatively the crack initiation and growth behaviors at $600^{\circ} \mathrm{C}$ fatigue, all crack depth were measured from SEM micrographs of the cross sectional surfaces of $600^{\circ} \mathrm{C}$ fatigued specimens(FB1, FB2, FB3, FB4). Figure 2 shows the histograms of the crack depth distribution observed on the cross sectional surfaces of the fatigued specimens at $600^{\circ} \mathrm{C}$. Very shallow cracks which are shorter than $10 \mu \mathrm{m}$ are not counted in these histograms. Surface cracks can initiate both at the grain boundaries and in the matrix, however they tend to propagate along grain boundaries. The tendency becomes clearer as a crack becomes longer.
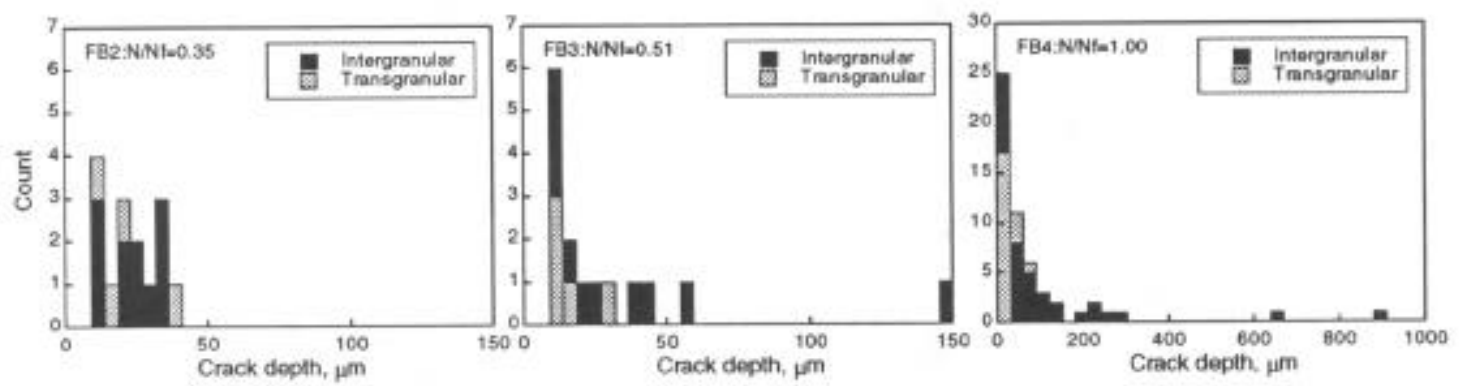

Figure 2 Changes in microcrack depth distribution as a function of $\mathrm{N} / \mathrm{Nf}$.

\section{Effect of Oxidation}

As described previously, there was definite difference in crack initiation and growth behavior between the fatigued specimens at $600^{\circ} \mathrm{C}$ and at room temperature. It has been known that intergranular cracking is caused and accelerated by selective grain boundary oxidation at high temperature in Ni-base superalloy(6). Figure 3 (a) shows the cross sectional surface of the failed
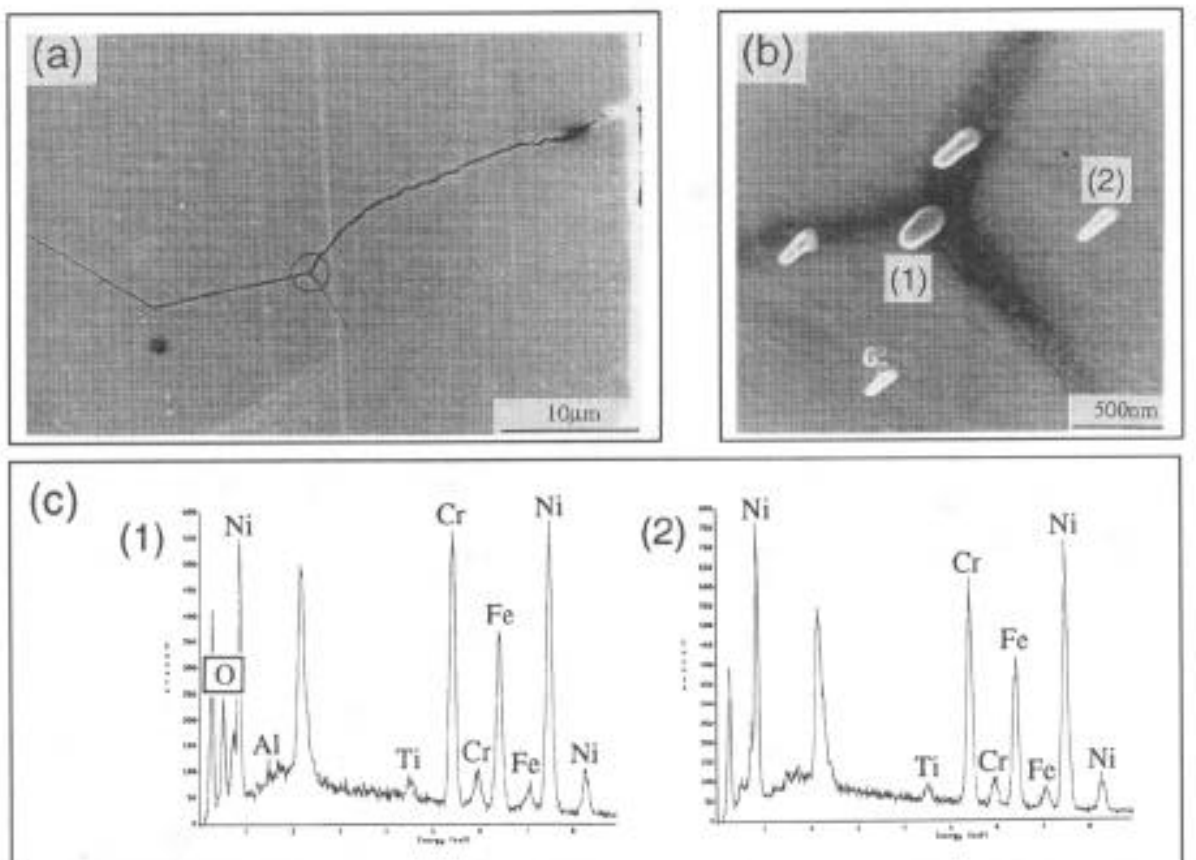

Figure 3 (a) SEM micrographs of affected grain boundaries in $600^{\circ} \mathrm{C}$ failed specimen(FB4), (b) Grain boundary at triple point selected for EDX analysis, (c) Results of electron beam spot analysis by EDX. 
specimen at $600^{\circ} \mathrm{C}$ (FB4) after mechanical polishing and no etching. As seen in this figure, the grain boundaries appear dark gray. At higher magnification (Figure 3(b)), the grain boundaries are not deformed and remain intact. This effect is due to the presence of low atomic number elements or compounds such as oxides at the grain boundary. In order to identify which elements were predominant at the affected grain boundaries, a chemical analysis was performed by EDX using electron beam spot analysis. From the obtained composition profile, shown in Figure 3(c), it is evident that oxygen is present on the grain boundary. This result indicates that the intergranular cracking in the fatigued specimens at $600^{\circ} \mathrm{C}$ is possible to be caused by a selective grain boundary oxidation. Also it is considered that because the crack initiation and growth is caused by cracking of these brittle oxidized grain boundaries, few slip bands were observed around cracks.

Damage Evaluation Based on Cracks

The number of cracks on the cross sectional surface(per unit gauge length: /mm) and maximum crack depth plottcd as a function of usage factor are given in Figure 4. Maximum crack depth in the failed specimen(FB4) is defined as the depth of a main crack observed on the fracture surface. As shown in this figure, both the number of cracks and maximum crack depth become large with increased usage factor. However, it is also found that maximum crack depth does not remarkably increase in early stage of the fatigue life, while cracks propagate rather fast in the latter half of the fatigue life. In addition, it is recognized that the maximum crack depth is as small as about $150 \mu \mathrm{m}$ even at a medium stage of the fatigue life. These results indicate that, in the main injector of the rocket engine, it is not easy to detect microcracks from the outer surface before the fatigue process reaches its last stage. Since surface cracks can not be a sensitive indicator of fatigue damage in its early stage, fatigue damage accumulation in microstructures is desired to be nondestructively evaluated. In the next section, we will focus on changes in etching characteristics of the microstructure due to fatigue damage accumulation.

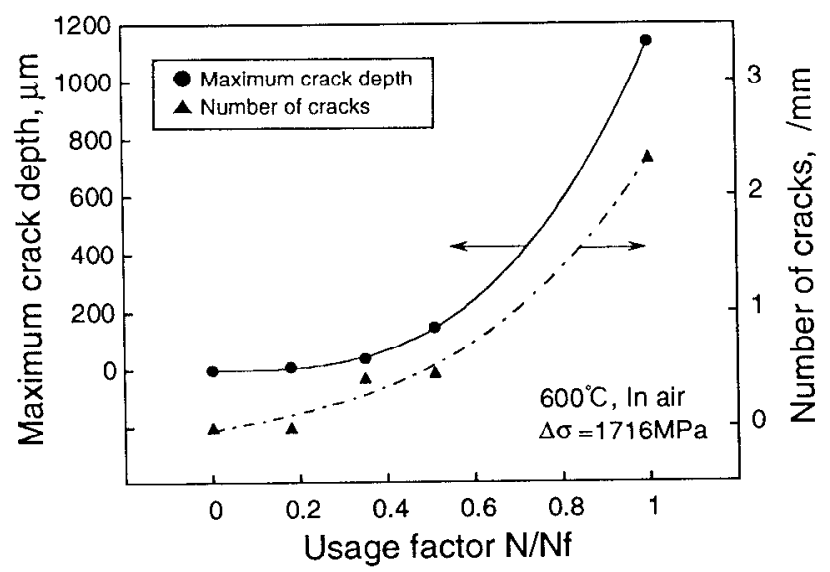

Figure 4 Maximum crack depth and number of cracks plotted as a function of N/Nf.

\section{B. Slip Bands Observation}

Changes in Ftching Characteristics

As described previously, ditch-like corrosion was found on the cross sectional surface of the fatigue specimen at room temperature(FBR.T175). The similar corrosion morphology was observed also in other fatigued specimens(FB1, FB2, FB3, FB4 and FBR.T135). Figure 5 shows examples of the etched cross sectional surfaces of FB4 and FBR.T175. Ditch-like corrosion and/or lines of pit-like corrosion are clearly observed on the surfaces, which didn't appear on the surface of the as-received material. However, these corrosion were observed much more remarkably in FBR.T175 than FB4. These ditch-like corrosion and/or lines of pit-likc corrosion were parallel to each other to a particular direction in each grain. Some ditches were also observed to be parallel with a twin. Since it was recognized that about half of them were observed to be at an angle of 40 
$\sim 50^{\circ}$ to the loading direction and some of them were observed to be parallel with the twin, they were considered to be the trace of persistent slip bands(PSBs) which are the characteristics of a fatigue damaged material. The preferential dissolution at or near PSBs during the etching seems to be caused by microstructural changes relating to the fatigue damage accumulation. The most possible mechanisms which may produce this preferential dissolution would be the accumulation of dislocation and its decoration effects by interstitial atoms at the vicinity of PSBs.
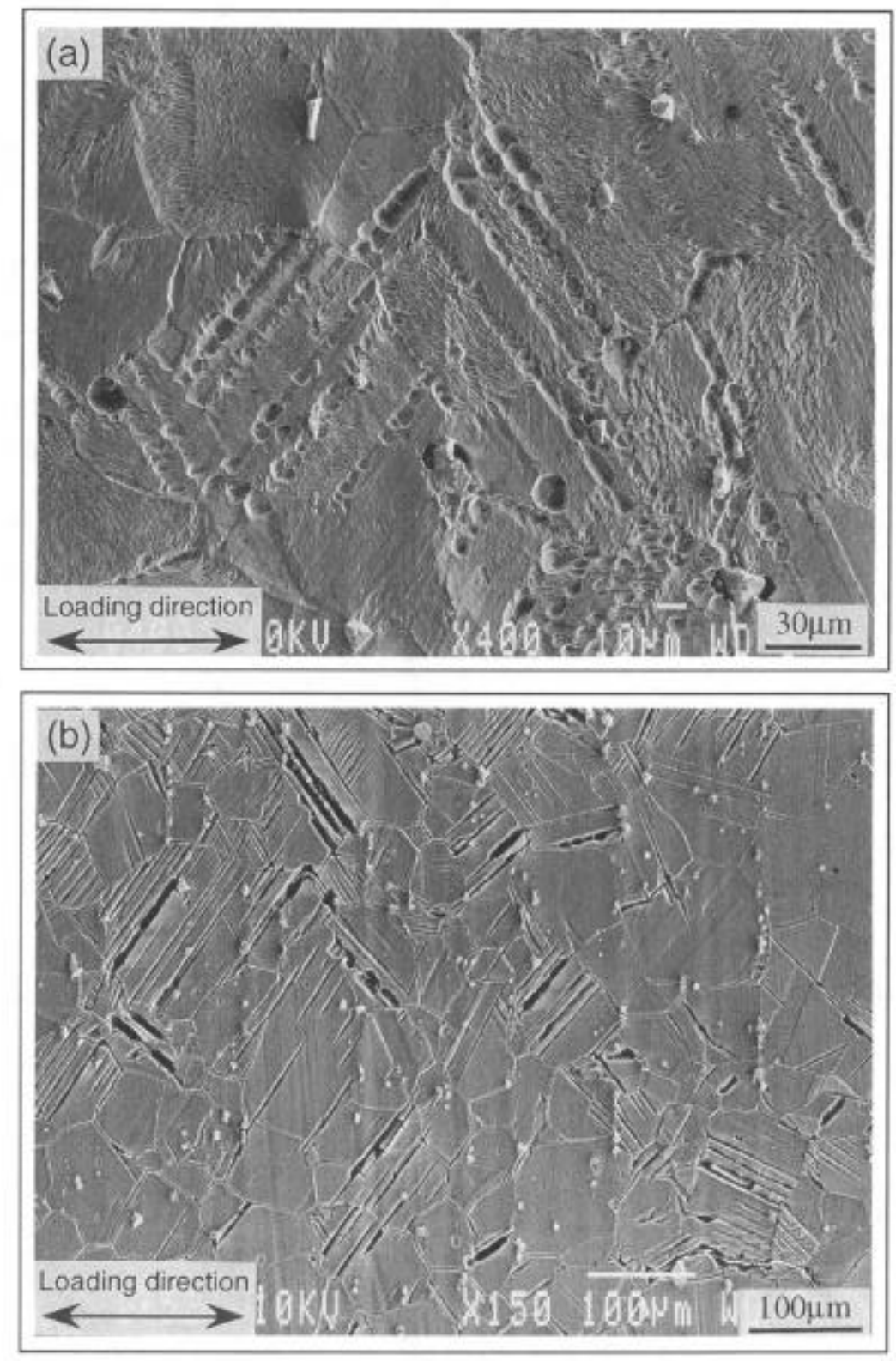

Figure 5 Examples of microcrack growth behavior : (a) Failed specimen at $600^{\circ} \mathrm{C}$ (FB4), (b) Failed specimen at room temperature (FBR.T175).

\section{Slip Bands Distribution}

As shown in Figure 5, the etching characteristics appears differently with each grain and each location on the cross sectional surface. We evaluated quantitatively the slip bands distribution in 
FBR.T175 and FBR.T135 which are fatigue fractured specimens at room temperature over stress range of $1716 \mathrm{MPa}$ and $1324 \mathrm{MPa}$ respectively. As shown in Figure 6, eleven lines were drawn perpendicularly to the loading direction, then counted the intersection of the measurement line with the slip bands. The obtained results are shown in Figure 7. Location of each histogram corresponds to actual SEM observation area. As shown in this figure, while in FBR.T175, the slip bands are distributed rather uniformly on the cross-sectional surfaces, in FBR.T135, the number of slip bands are smaller in the interior region of gauge section than near the gauge surface. It is known that local slip in grain size scale occurs ununiformly, while the whole specimen is uniformly deformed in macroscopic scale. It is also known that this local deformation is less pronounced with increased stress range. From the observation of above, the same tendency was observed. The slip bands were distributed more uniformly in FBR.T175 than FBR.T135. In addition, it was found that in both specimens the slip bands accumulation was more pronounced on the opposite side of the main crack initiation sile. This would be because the cross sectional area of specimen was decreased as the main crack propagation and plastic stress was locally concentrated at the ligament region.

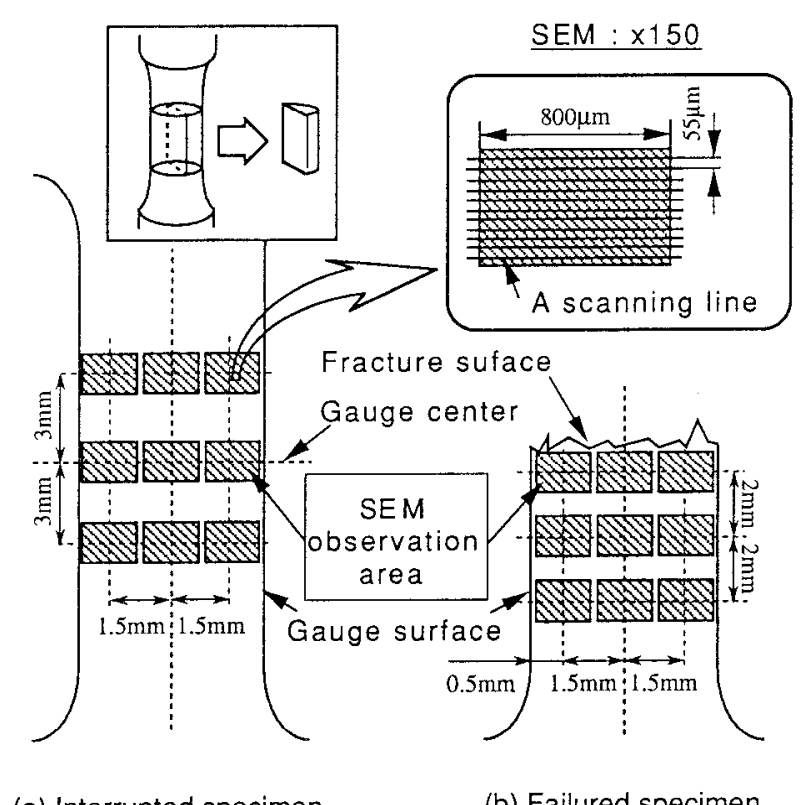

(a) Interrupted specimen

(b) Failured specimen

Figure 6 Observation area of slip bands in fatigue specimens.

\section{Damage Evaluation Based on Slip Band Density}

As described above, the etching characteristics seems to depend on grain properties and locations inside a specimen. These results suggested that the degree of the fatigue damage accumulation varied with grains and/or locations in the specimens. In fact, as shown in Figure 7, the slip bands are differently distributed with locations in the specimen. In order to determinc quantitatively the slip bands formed in the fatigue damage accumulation process, the number of slip bands crossed by a measurement line of unit length $(1 \mathrm{~mm})$ were defined as "slip band density" and the slip band densities were measured for the $600^{\circ} \mathrm{C}$ fatigued specimens. Figure 8 shows the slip band density plotted as a function of the usage factor N/Nf. As shown in this figure, the slip band density can be uniquely correlated with the life fraction N/Nf. Since information of slip band density of materials interior is not available in case of fatigue damage evaluation in actual components, the fatigue damage must be evaluated from information of the surface of the components. The slip band densities measured near the surface region are also plotted in Figure 8 , where a good correlation also can be seen. These results suggest that the fatigue damage 

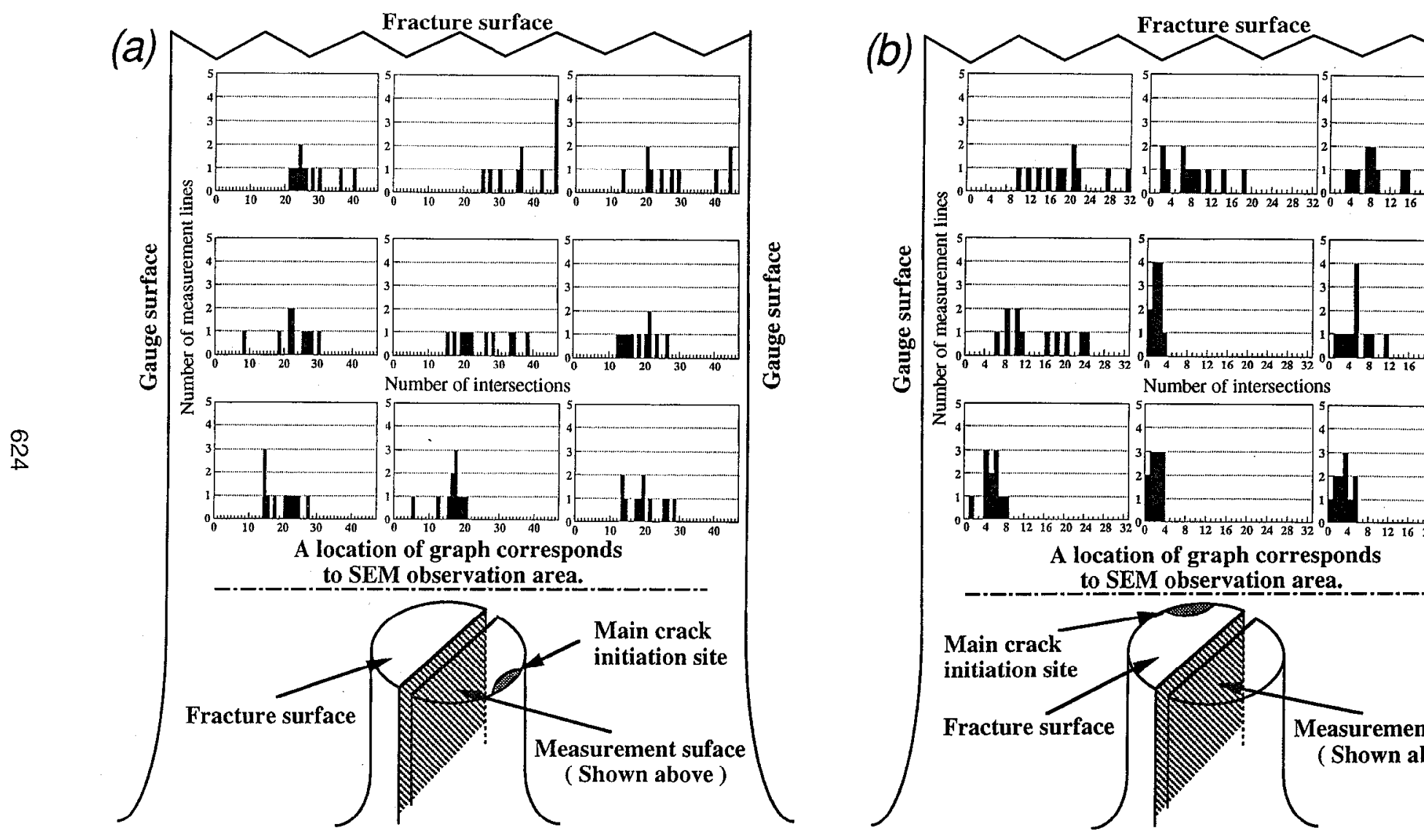

Figure 7 A distribution of slip bands : (a) FBR.T175, (b) FBR.T135. 
represented by $\mathrm{N} / \mathrm{Nf}$ can be evaluated by the chemical etching technique and, as shown in Figure 8 , the damage can be evaluated from the early stage to the last stage of fatigue life. In addition, Figure 9 shows the results including the fatigued specimens at room temperature. As shown in this figure, the slip band density of FBR.T135 is smaller than that of FBR.T175, in spite of the longer fatigue life. These results reflect the fact that slip occurs in more limited numbers of particular grains at lower stress level. Furthermore, it also seems that the slip band density value in FBR.T175 can obtained by extrapolating the results obtained by the $600^{\circ} \mathrm{C}$ fatigued specimens to a high usage factor. This suggests that the temperature dependence of slip band density value is small, while this value strongly depends on the loading stress and reflects the number of fatigue cycles.

On the other hand, it has been well known that the fatigue damage accumulation can be given by Coffin-Manson relationship and in low-cycle fatigue a microcrack density and electrochemical property of materials are uniquely correlated with Coffin-Manson type parameter(7). It is considered that in order to generalize this chemical etching technique, the chemical etching property of slip bands should be correlated with not only the usage factor N/Nf but also CoffinManson type parameters.

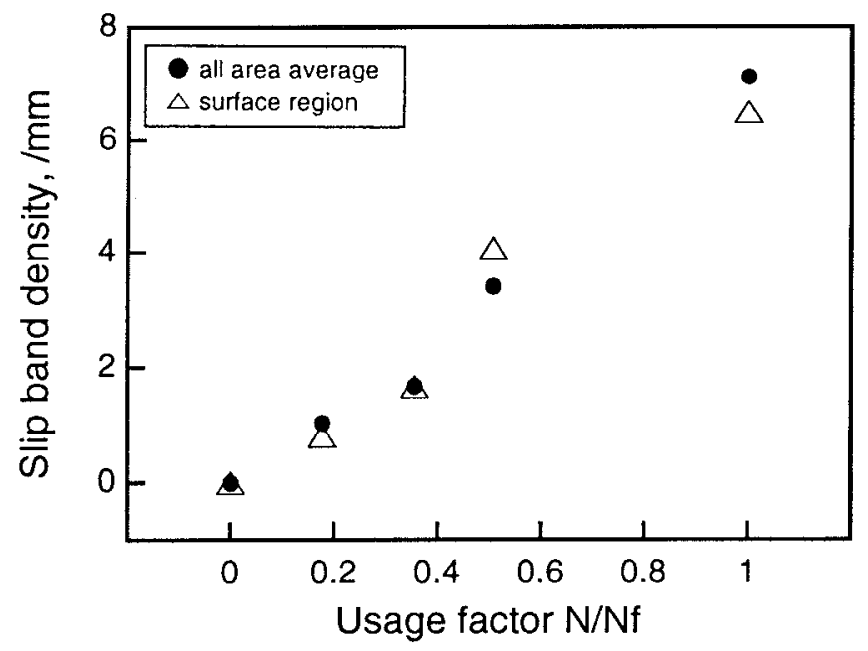

Figure 8 Slip band density plotted as a function of N/Nf.

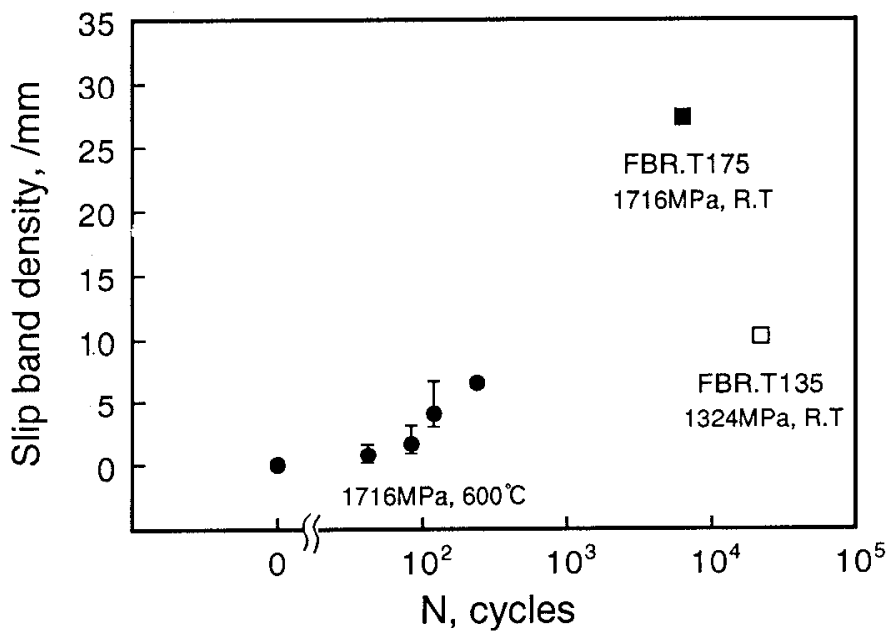

Figure 9 Slip band density plotted as a function of $\mathbf{N}$. 


\section{Damage Evaluation Based on Slip Bands and Cracks}

As described above, both the crack-based parameters, e.g. maximum crack depth and number of cracks, and the microstructurc-bascd indicator, namely slip band density can be correlated with fatigue life fraction. Correlation between the two parameters, maximum crack depth and slip band density, can been seen in Figure 10, where maximum crack depth is plotted as a function of slip band density. Cracks are not very active until $\mathrm{N} / \mathrm{Nf}$ reaches about 0.4 , however slip band density increases from the initial stage. Crack depth takes off at around $\mathrm{N} / \mathrm{Nf}=0.5$ and the main crack propagates rather fast resulting final failure.

Sensitivity of crack detection techniques is getting improved, for example, current developed ICFPD (Induced Current Focusing Potential Drop) technique is capable to detect a crack as small as $0.5 \mathrm{~mm}$ existing on the reversed side of $3.5 \mathrm{~mm}$ thick Inconel 718 plate $(8)$. However, the sensitivity is not still high enough to evaluate fatigue cracks in the initial stages of the life.

Based on the results in Figure 10, it may be concluded that it is not easy to detect cracks directly before the fatigue process reaches its last stage, however we can monitor the fatigue damage accumulation based on slip band density from the early stage to the last stage of fatigue life.

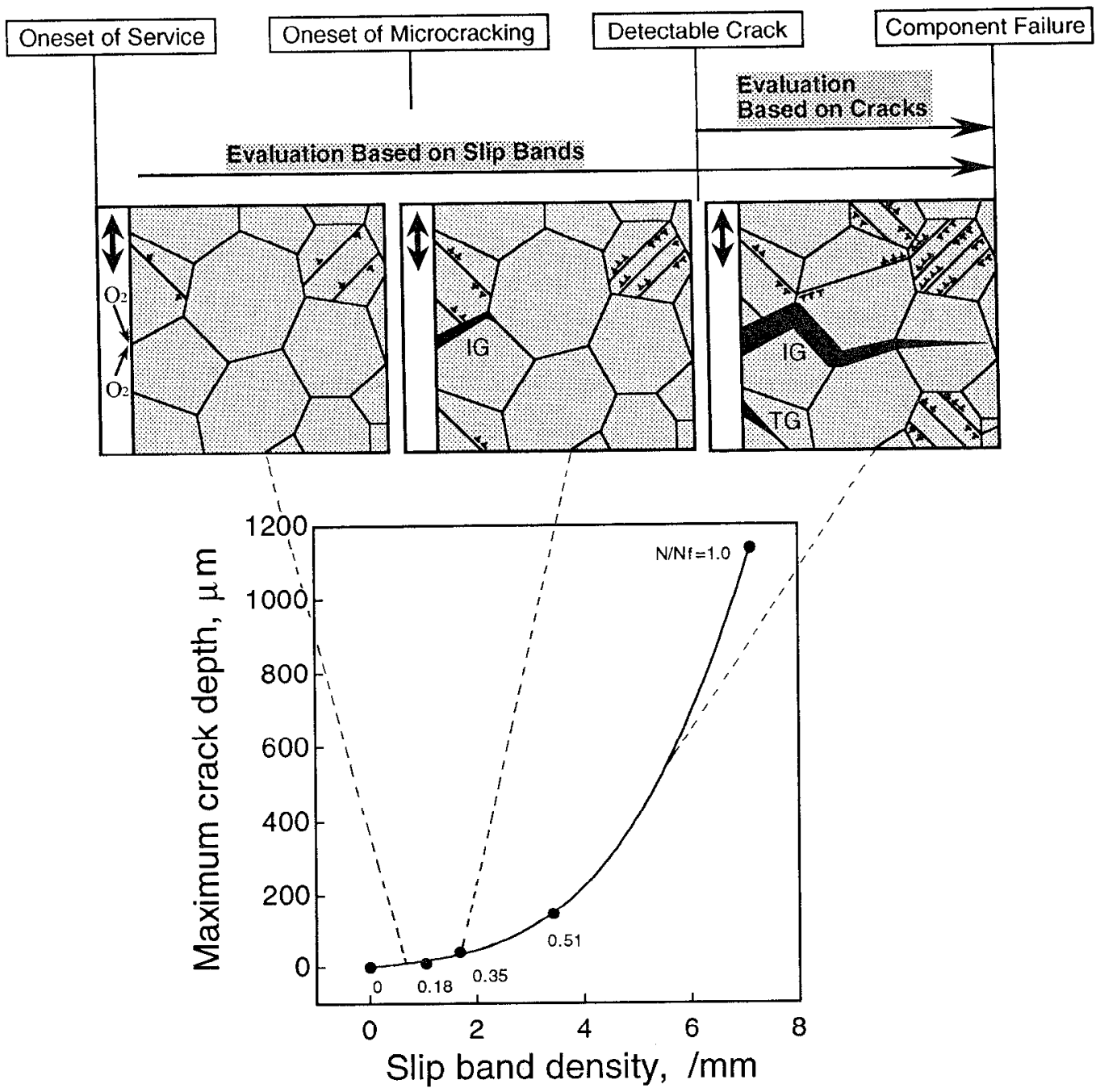

Figure 10 Maximum crack depth plotted as a function of slip band density. 


\section{CONCLUSIONS}

Low-cycle fatigue tests were carried out on a Ni-base superalloy Inconel 718 at $600^{\circ} \mathrm{C}$ to investigate a process of fatigue damage and develop a novel technique for nondestructive evaluation of it. The following concluding remarks can be drawn:

(1) Cracks initiates at grain boundaries and propagates mainly along grain boundaries under fatigue loading at $600^{\circ} \mathrm{C}$ in air over stress range of $1716 \mathrm{MPa}$, and it is possible to be caused by a selective grain boundary oxidation.

(2) The number of cracks and maximum crack depth become large with increased the fatigue life fraction N/Nf. However, maximum crack depth does not remarkably increase in early stage of the fatigue life, while cracks propagate rather fast in the latter half of the fatigue life.

(3) Slip bands are preferentially dissolved on the cross sectional surface of the fatigued specimens by a chemical etching with a solution of $\mathrm{HCl}: 100 \mathrm{ml}, \mathrm{H}_{2} \mathrm{O}: 80 \mathrm{ml}, \mathrm{H}_{2} \mathrm{SO}_{4}: 5 \mathrm{ml}, \mathrm{CuSO}_{4}: 20 \mathrm{~g}$. The slip band etching characteristics appears differently with each grain and each location on the cross sectional surface.

(4) The slip band density can be uniquely correlated with the fatigue life fraction N/Nf. The fatigue damage represented by $\mathrm{N} / \mathrm{Nf}$ can be evaluated by the chemical etching technique and the damage can be evaluated from the early stage to the last stage of fatigue life.

\section{ACKNOWLEDGEMENTS}

The authors wish to express their gratitude to National Space Development Agency of Japan and Central Res. Inst. of Elect. Power Indust. for providing the materials and specimens used in this work. A part of this work was supported by Grant-in Aid for Scientic Research (T. Shoji, Grant No. 06452143), The Ministry of Education, Science and Culturc.

\section{REFERENCES}

(1) K. Hasegawa et al, "Improvement of Fracture Toughness and Low-Cycle Fatigue Life for INCONEL 718 Welded Joint in the LE-7 Rocket Engine Main Injector," Transaction of the Japan Society of Mechanical Engineerings A, 61-588 (1995), 1707- 1712.

(2) K. Hasegawa et al, "Nondestructive and Analytical Creep and Fatigue Life Evaluation of INCONEL718 in the LE-7 Rocket Engine Main Injector," Transaction of the Japan Society of Mechanical Engineerings A, 61-588 (1995), 1701-1706.

(3) S. Sakurai et al, "A Remaining Life Prediction Method on the Basis of Micro-Crack Initiation and Growth Behavior under Creep-Fatigue in Plain Specimen of 316 Stainless Steel," Juurnal of Society of Materials Science Japan, Vol.35 (1986), 170-175.

(4) Y.Ito and Y. Furuya, "Nondestructive Material Evaluation by Barkhausen Noise Analysis Part 2: Application of Barkhausen Noise Method to Actual Problems," Iournal of JSNDI, Vol.45 (1996),91-98.

(5) J.S. ZHANG et al, " Design and Development of Hot Corrosion-Resistant Nickel-Base SingleCrystal Superalloy by the $d$-Electrons Alloy Design Theory: Part II. Effects of Refractory Metals $\mathrm{Ti}$, Ta and $\mathrm{Nb}$ on Microstructures and Properties," METALLURGICAL TRANSACTIONS A, Vol.24A (1993), 2451-2464.

(6) M.M. Morra, " Stress Accelerated Grain Boundary Oxidation of Incoloy Alloy 908 in High 
Temperature Oxygenous Atmospheres" (Ph.D.thesis, MIT, 1995), 23-42.

(7) T. Shoji, Y. Kawamori and Y.Watanabe, " Nondestructive Detection of Fatigue Damage Accumulation of RPV Steel" (Proceedings of the Sixth International Symposium on Environmental Degradation of Materials in Nuclear Power Systems - Water Reactors -, San Diego, California, August 1-5, 1993), 433-441.

(8) Y. Sato et al, "Study on Automatic Inspection System and Improvement of Detection Sensitivity of Defects by Induced Current Focusing Potential Drop Technique" Proceedings of JSNDI (Japan Society of Nondestructive Inspection) Spring Conference 1997, Tokyo, May 15-16, 1997), To be published. 